\title{
Radioablation and suture fixation of advanced grades of hemorrhoids. An effective alternative to staplers and Doppler guided ligation of hemorrhoids
}

\author{
P. J. Gupta \\ M.S. (Gen. Surgery). Consulting Proctologist. Fine Morning Hospital and Research Center. Nagpur, India
}

\begin{abstract}
Background: for advance grades of symptomatic hemorrhoids (grade III and IV) the author has innovated a procedure called radiofrequency ablation and fixation of hemorrhoids. The procedure is performed as a day care surgery.

Patients and methods: the surgical technique and clinical follow-up of patients operated by this technique are presented. An Ellman dual frequency radiofrequency generator was used for ablation, which was followed by suture fixation of the hemorrhoids. Patient satisfaction score was assessed using a visual analogue scale. The results of this procedure are presented and are compared with the results of published data of stapled hemorrhoidopexy and Doppler guided hemorrhoidal artery ligation procedures.

Results: between 1998 and 2005, 2,376 patients were operated with this technique. Patient's mean age was 34 years and 1,438 patients were males. The postoperative complication rate was $3.5 \%$, which included secondary bleeding, retention of urine and perianal thrombosis. The recurrence rate was less than $1.5 \%$. The satisfaction score was 9.2 on VAS.

Conclusions: radiofrequency ablation and fixation of hemorrhoids is a technique that results in less postoperative pain, shorter hospital stay, and early return to normal activity. It seems to be a better alternative to stapled hemorrhoidopexy or Doppler guided hemorrhoidal artery ligation with regard to effectiveness and symptomatic relief on long term.
\end{abstract}

Key words: Stapled hemorrhoidopexy. Doppler guided hemorrhoidal artery ligation. Radiofrequency. Fixation. Hemorrhoids. Pain.

Gupta PJ. Radioablation and suture fixation of advanced grades of hemorrhoids. An effective alternative to staplers and Doppler guided ligation of hemorrhoids. Rev Esp Enferm Dig 2006; 98: 740-746.

Received: 08-05-06

Accepted: 10-05-06.

Correspondence: P. J. Gupta. M.S. (Gen. Surgery). Consulting Proctologist. Fine Morning Hospital and Research Center. Gupta Nursing Home. D/9, Laxminagar. Nagpur, India. Fax: 91712 2547837. e-mail: drpjg_ngp@sancharnet.in; drpjg@yahoo.co.in

\section{INTRODUCTION}

Symptomatic hemorrhoids affect about $4.4 \%$ of the population and of these almost one-third present to surgeons for treatment. For advanced grades of hemorrhoids, the treatment of choice remains surgical excision. The open and closed hemorrhoidectomy (1) are the most preferred procedures for prolapsing hemorrhoids. However, both these techniques are associated with long and painful postoperative course (2), prolonged convalescence period with reported incidences of complications like hemorrhage, anal stenosis, and recurrence.

The control of post-hemorrhoidectomy pain has always been the main concern for the surgeon, and different techniques have been attempted in this direction. This has led to introduction of newer techniques like stapled hemorrhoidopexy (SH) and Doppler guided hemorrhoidal artery ligation (DGHAL), which claim success in minimizing pain, reducing bleeding, and avoiding postoperative complications. However, their effectiveness, safety, and long-term results are still open to debate.

Hemorrhoids are regarded as cushions of fibrous and vascular tissue in the anal canal, which help in maintaining the anal continence. These cushions produce symptoms when there is a pathological enlargement and fragmentation of the connective tissues within the cushions, leading to their distal displacement. A method, which would help the hemorrhoidal cushions to return to their normal size and at their usual positions while obscuring the hemorrhoidal vascular components without their excision, should be a rational approach.

In an attempt in this direction, fixation or suturing of the hemorrhoids to repose the hemorrhoidal cushions back to their normal positions is in practice since long time. Farag (3) was first to introduce a 'pile suture' method. He used three interrupted sutures to secure the hemorrhoids in place. Awojobi (4), while using Farag's pile suture technique; operated patients with prolapsing 
hemorrhoids on an outpatient basis to achieve $96 \%$ success. By a similar technique, Bhansali and Kale (5) could achieve good results. In another study, a series of 300 patients were successfully operated by this method (6).

Serdev (7) advocated a method of suturing ligation of hemorrhoids without their excision. He used absorbable sutures, placing them above the dentate line to fix the anal cushion back to the internal sphincter. He claimed that the stitch reduces the hemorrhoidal blood supply and obliterates the bulk of the pile mass.

On the other hand, in-situ thermal ablation of the hemorrhoids to eliminate the vascular components of anal cushions is in practice since the day of Hippocrates, who suggested burning of hemorrhoids (8). Infra red heat coagulation (9), bipolar diathermy destruction (10), Nd: YAG or $\mathrm{CO}_{2}$ laser coagulation (11), direct current probe (12) and coagulation by heater probe (13) are few other techniques, where heat is used as a medium to destroy hemorrhoids.

Recently, radiofrequency coagulation has emerged as a technique that results in immediate reduction of blood flow of the tissue under focus of these waves and thereafter healing is induced by way of cicatrisation (14). Radiofrequency waves ablate tissue by converting radio waves into heat. The alternating current passes down from an uninsulated electrode tip to the targeted tissues and generates changes in the direction of ions within the tissue fluid. This creates ionic agitation and frictional heating. This process drives out the extra and intracellular water from the tissue, and ultimately destroys the tissue by coagulative necrosis (15). This phenomenon is called as cellular volatilization (16). The result of this coagulation is fibrosis and fixation of the ablated tissues.

We attempted to blend the best of the above two methods to achieve a synergic effect. The ablation was carried out using radiofrequency and thereafter the hemorrhoids were plicated (sutured).

The present study describes the procedure of ablation of hemorrhoids using radiofrequency waves followed by fixation (RAF) of the anal cushions to the internal sphincter.

The aim of this study was to assess postoperative pain, time to return to work, early and late complications and the outcome of this novel technique.

\section{MATERIALS AND METHODS}

During a period of 7 years (from May 1998 to June 2005) 2,376 patients with prolapsing hemorrhoids admitted for elective surgery were enrolled for this study. The patient demographics are given in table I.

Patients operated for hemorrhoids in the past, patients taking anti-platelet medicines or having acute thrombosed hemorrhoids were excluded from the study.

Detailed clinical and anoscopic examination was carried out before the procedure. An informed consent was obtained from all the patients after explaining them the details about the procedure.
Table I. Patient demographics

\begin{tabular}{lc}
\hline Mean age in years (SD) & $34(9.4)$ \\
Men: Women ratio & $1,428: 948$ \\
Mean duration of disease in years (SD) & $4.7(1.1)$ \\
Hemorrhoid degree* $3 / 4$ & $1,934 / 44$ \\
& \\
Symptoms in number of patients & \\
Bleeding & 2,287 \\
Pain & 942 \\
Pruritus & 438 \\
Discharge & 316
\end{tabular}

* Degree after Goligher

$30 \mathrm{ml}$ of lactulose (Duphalac) was given on the night before the procedure. Patients were operated under a short general anesthesia or caudal block.

The Radio Surgical Unit. An Ellman dual frequency $4 \mathrm{MHz}$ radiofrequency generator (Ellman International Oceanside, New York) was used for ablation of hemorrhoids. The unit is provided with a handle to which different electrodes could be attached to meet the requirements of the procedure (17). The power output intensity to be delivered by the device could be pre-set to range between 1 and 100. A ball electrode meant for coagulation was used in this procedure.

\section{Operative technique}

The procedure was performed with the patient in a lithotomy position.

The three skin tags corresponding to three principle sites of hemorrhoidal cushions, namely 3, 7 and 11,0 clock position were held with artery forceps and retracted out to visualize the hemorrhoids. Beginning at the pedicle, the complete hemorrhoidal mass was evenly coagulated by gradually rotating the ball electrode. The output power intensity of the radiofrequency generator was so adjusted as to produce shrinkage of the tissues without creating a char. The gradual change of hemorrhoids to dusky white color (blanching) indicated satisfactory coagulation necrosis. Any associated secondary (18) hemorrhoids were simultaneously ablated with precaution of sparing the normal anal mucosa between the hemorrhoids. Care was taken to avoid charring of rectal mucosa or the anoderm by targeting the hemorrhoids alone. These precautions helped us avoid undue fibrosis and anal narrowing, a complication, which is often encountered after such procedures (19).

After achieving the desired ablation, the hemorrhoidal mass was over sewn with 1-0 chromic catgut on $45 \mathrm{~mm}$ needle (No. 4246 Ethicon US). Beginning from the most distal end of the hemorrhoid at the anal verge, the suturing was carried towards the pedicle in a continuous locking manner. A knot was tied at the hemorrhoidal pedicle to secure this fixation. All the hemorrhoids were dealt with in a similar fashion in one session. 
The patients were assessed after 6 hours of the procedure and were discharged if they were found comfortable with regard to pain and reporting no difficulty in passing urine. In the postoperative course, patients were given a standard regimen of $20 \mathrm{ml}$ lactulose at bedtime for 4 weeks. Pain was controlled with tablets of tramadol hydrochloride (Domadol) $50 \mathrm{mg}$ two times a day with an extra dose on demand, but never more than three per day.

Additional procedures were performed in 234 patients. These included removal of external skin tags $(n=123)$, excision of fibrous anal polyps $(n=29)$, sphincterotomy (for chronic anal fissures) with removal of sentinel pile $(\mathrm{n}=52)$ and low anal fistulotomy $(\mathrm{n}=30)$. All these procedures were accomplished using appropriate electrodes available with the radiofrequency device.

For pain assessment, we used a visual analogue scale (VAS) from 0 to 10 , with zero referring to absence of pain and 10, the maximum pain experienced in the past by the patient.

Outpatient follow up was carried out at 1,2 and 4 weeks after the procedure to assess the duration of postoperative pain, time to return to work, wound healing time and early complications like bleeding, urinary retention, seepage and continence disorder. They were subsequently called after 1 year to note late complications like anal stenosis, recurrence of hemorrhoids and development of external skin tags or any new symptoms. These findings were recorded by an independent observer. A satisfaction grading using a visual analogue scale $(0=$ not at all satisfied, and $10=$ fully satisfied) was performed at 1 year follow-up in the office.

\section{RESULTS (Table II)}

The actual operative procedure took about 6-9 minutes to complete. A mean of 64 seconds of radiofrequency ablation was required for ablation of each hemorrhoid.

-Post-procedure pain. All the patients had a postdefecation pain which lasted for an average of 35 minutes (range 20-120 minutes) during the first postoperative defecation and for 9 minutes (range 5-30 minutes) on the $7^{\text {th }}$ postoperative day. In $90 \%$ patients, the pain was within tolerable limits (pain score of 1 to 5 on the visual analogue scale) (Fig. 1).

-Pain at rest. The mean pain score in the first week

Table II. Peri- and postoperative findings after radiofrequency ablation and fixation of hemorrhoids

\begin{tabular}{lc}
\hline Observations & Findings \\
\hline Operative time (minutes) & $7(5-11)$ \\
Mean hospital stay (hours) & $13(7-22)$ \\
First bowel movement (hours) & $15(12-25)$ \\
Hospital stay (hours) & $17(6-23)$ \\
Time to return to work (days) & $12(6-17)$ \\
Analgesic requirement (number of tablets) & $19(13-32)$ \\
\hline
\end{tabular}

Values are mean (range).

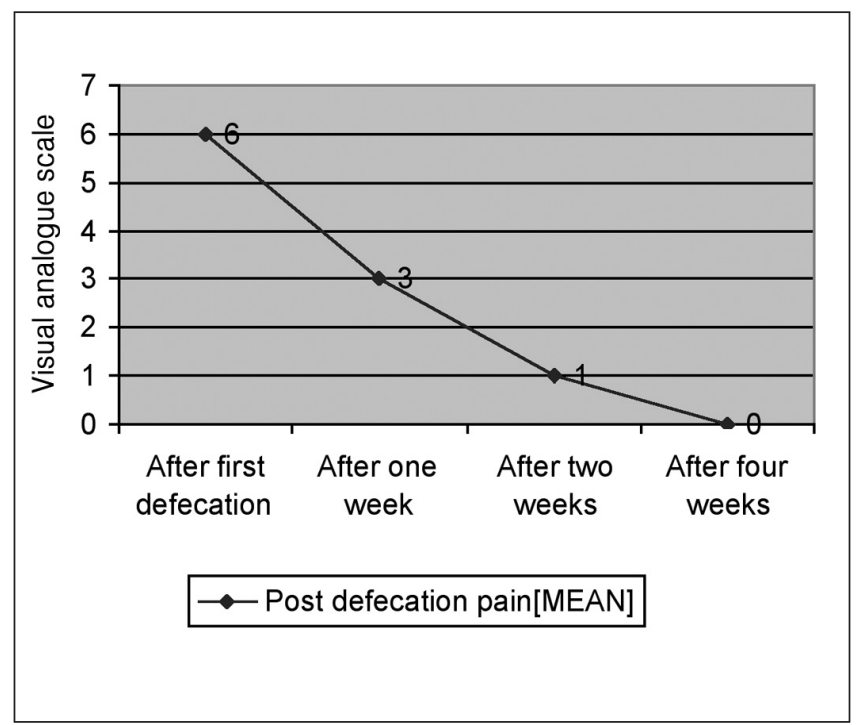

Fig. 1.- Post-defecation pain score after radiofrequency ablation and fixation of hemorrhoids.

was 3 (range 1 to 4 ) on the visual analogue scale and 2 (range $0-3$ ) in the $2^{\text {nd }}$ week. $80 \%$ patients did not require any additional dose of analgesics. In the remaining, one extra dose of tramadol provided adequate relief. Pain was more in the patients having grade 4 hemorrhoids or in whom additional procedures were performed (Fig. 2).

-Bleeding. 1,458 patients complained of post-defecation bleeding, ranging between a mere smearing of the stool and small drops. It stopped by its own within a week. 44 patients continued to have minor bleeding as long as up to 2 weeks. Rest of the patients did not face any bleeding right from the very first defecation.

-Bowel movements. $81 \%$ patients could pass stool on the postoperative morning. The defecation though painful, was easy and effortless.

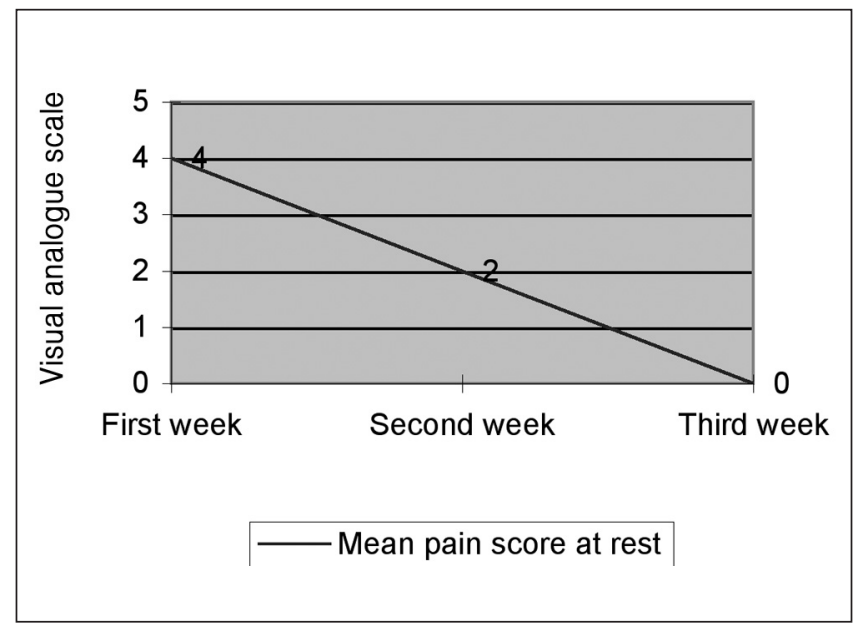

Fig. 2.- Pain score at rest after radiofrequency ablation and fixation of hemorrhoids. 
-Duration of incapacity to work. 1,042 patients could resume their routine as early as on the seventh postoperative day. 547 patients could join their duties after 10 days. The remaining patients required about 2 weeks time to return to work.

\section{Complications}

-Retention of urine. 53 male patients had retention of urine. 24 of them were relieved after a warm sitz bath. The remaining patients required catheterization. No dwelling catheter was needed.

-Hemorrhage. 26 patients returned with spontaneous rectal bleeding between the 7 and $14^{\text {th }}$ postoperative day. They were readmitted. Seventeen of them responded to conservative treatment with local compression and haemostatic medication. However, the bleeding points needed to be secured in the remaining nine patients under anesthesia. They had an uneventful recovery thereafter.

-Perianal thrombosis. 74 patients developed perianal thrombosis at the sites of hemorrhoidal fixation. These were tender in the first two weeks, but thereafter the discomfort reduced. Complete resolution of this thrombus took about 3-4 weeks.

- Anal narrowing. Spastic sphincter contractions were found in 16 patients during digital examination at the 4-week follow-up. Digital dilatation was performed in the office. Such narrowing was not noticed in the subsequent follow-up.

-Wound healing. This was evaluated by inserting a welllubricated pediatric anoscope. The wounds were found healed in 1,644 patients at the follow-up after 14 days and in 231 patients at the 4-week follow-up. Wounds of the patients undergoing additional procedures needed even more time to heal.

-Incontinence. 49 patients complained of incontinence for flatus in the first two weeks, but it was self-limiting. None of the patients complained of fecal incontinence.

None of the patients developed any septic complication like wound infection, abscess, or fistula formation.

During anoscopic examination at 4 weeks, the hemorrhoidal mass looked shrunken and segmented. The mass was found to be replaced by fibrous bands in the subsequent follow-up.

-One-year follow-up. 296 patients were lost to follow-up.

- Late complications. External skin tags -96 patients developed external skin tags. They were reassured about the benign nature of these tags. However, due to persistent complaint from 32 patients, the tags were removed in the office under local anesthesia.

-Recurrence. 26 patients complained of intermittent bleeding per rectum. They were found to have non-prolapsing hemorrhoids. Rubber band ligation was carried out in these patients successfully.
In another 38 patients, anoscopy showed presence of anal papillae. 14 of these patients complained of symptoms like pruritus and post-defecation discomfort. Symptomatic treatment relieved their complaints.

-Patient satisfaction score. The patients satisfaction score was 9.2 on visual analogue scale.

\section{DISCUSSION}

The concern regarding the management of postoperative pain, need for long-term wound care and fear of complications following hemorrhoidectomy had lead the surgeons to modify surgical techniques using various innovative approaches. Surgical or medical means to reduce sphincter muscle spasm, different types of analgesia and anesthesia and use of antibiotics to reduce pain have been tried. Despite these approaches, the primary cause of pain, the trauma to the pain sensitive perianal skin and anal mucosa during excision of hemorrhoids persists and reduction in pain is usually limited.

In contrast to the excisional techniques, the procedure of radiofrequency ablation and fixation of hemorrhoids does not cause any trauma to the perianal skin. While the anal mucosa is exposed to the treatment, the area of application being only proximal to the sensitive dentate line, the postoperative pain is minimal.

Two techniques namely, stapled hemorrhoidopexy and Doppler guided hemorrhoidal artery ligation have recently been introduced to curb post-treatment pain. Through a few controlled trails, these techniques have come to be associated with less postoperative pain and an earlier return to normal activity (20). However, some problematic areas surrounding these procedures have been reported from some other studies. The initial enthusiasm generated by these techniques is now being tempered by serious concern relating to long-term efficacy and complications of serious nature $(21,22)$.

In stapled hemorrhoidopexy, a circumferential strip of rectal mucosa is removed using a circular stapler so that the prolapsing hemorrhoidal cushion can be lifted up and sutured back. However, elimination of this strip of rectal mucosa does not necessarily mean that the anal mucosa will stretch up from the anal canal, and instead, the more redundant circumferential rectal mucosa may be pulled down into the anal canal, leaving the longitudinal anal fold containing the hemorrhoid unattended (23).

It is presumed that with the removed strip of rectal mucosa, the hemorrhoidal vessels will also be disrupted to help arresting vascular supply to the hemorrhoids. However, a vascular Doppler study by Kolbert (24). Noticed that in $80 \%$ of patients who had undergone a stapled hemorrhoidopexy, few uninterrupted branches of the hemorrhoidal vessels were still present.

If this study is to be believed, then the mechanism of control of hemorrhoidal bleeding by staplers remains questionable. 
While some distinguished authors' state that stapled hemorrhoidopexy ( $\mathrm{SH}$ ) is the best surgical technique for symptomatic hemorrhoids (25), other surgeons have concluded that it does not seem to offer significant advantages in terms of reduced hospitalization or symptom control in long term (26).

While most surgeons agree that, the convalescence after SH is shorter $(27,28)$. few others could not demonstrate an earlier return to work (29). The operation is defined as "easy" by some authors (30) whereas for few others, it is "demanding" (29).

Rates of complications after SH range from 6 to $31 \%$ (30-32), and surprisingly, complications reported after $\mathrm{SH}$ are similar to those of open hemorrhoidectomy and in addition, other complications like hemorrhoidal thrombosis (33), rectal anastomotic leakages with pelvic sepsis, rectal obstruction, retrorectal hematomas, rectal perforation (34), retroperitoneal sepsis (35) and Fournier gangrene (36) have also been reported.

Such complications were not encountered in any of the patients treated with RAF technique.

Another non-excisional procedure is a Doppler guided hemorrhoidal artery ligation, which was introduced by Morinaga and his associates (18). The advocates of this technique claim this technique to be a painless office procedure, useful in all grades of hemorrhoids with a negligible period of convalescence $(37,38)$.

This procedure, which is also termed as trans-anal hemorrhoidal de-arterialization, employs a specially designed proctoscope coupled with a Doppler transducer to allow identification and suture ligation of the hemorrhoidal arteries.

The concept of this procedure is probably based on the presumption that ligation of the branches of hemorrhoidal artery while arresting the bleeding, will cause shrinkage of the hemorrhoids (39).

While it has been accepted that hemorrhoidal disease results from the pathological enlargement and distal displacement of the hemorrhoidal cushions, the concept of ligation of hemorrhoidal artery to curb the hemorrhoids does not hold true any longer. While studying the branching pattern of the superior hemorrhoidal artery, it was found that the hemorrhoids were being supplied by few additional branches of hemorrhoidal artery entering from the posterior wall of the rectum that were not accessible to ligation by the doppler method. This questions the completeness of the procedure (40).

It is known that a free anastomosis exists between branches of superior, middle and inferior hemorrhoidal vessels. Thus, mere ligation of branches of superior hemorrhoidal artery does not ensure complete blockage of blood supply to the hemorrhoids.

While it is agreed that the convalescence period with DGHAL is very short, there is no unanimity that it could be performed without the aid of anesthesia (41), and that is does not require hospitalization (42). The procedure is not found effective in controlling prolapse of hemorrhoids
$(12,41,43)$, and it does require additional procedure like rubber band ligation for fixation of the hemorrhoids to eliminate their prolapse (44). The success rate reported with this technique varies between 62 and $88 \%$ on a shortterm follow-up of less than one year $(41,44)$.

It can be gathered from the above discussion that both SH and DGHAL are modalities of treating hemorrhoids that leave behind the pathology (the hemorrhoids) partly unattended. When a patient complains again of hemorrhoidal symptoms after SH or DGHAL, the symptoms could not be called recurrent. This is because the hemorrhoids in fact are not removed. What is recurrent is that the patient still complains of the problem that brought him to the doctor in the first place. They fail to deal with the external hemorrhoids or associated anal canal problem unlike the conventional hemorrhoidectomy or the radiofrequency procedure $(45,46)$.

In conclusion, it seems that the only advantage of $\mathrm{SH}$ or DGHAL is the lesser postoperative pain. As this generally is the main cause for fear for those who undergo an operation of hemorrhoids, the patients themselves strongly feel inclined to opt for these procedures. A strong media campaign advertising the virtues of these procedures being painless and almost without recurrence also does influence the opinions.

The procedure of radiofrequency ablation followed by fixation achieves the goals, which are commonly considered necessary in attending an advanced hemorrhoidal disease. Hemorrhoidal fixation helps attaching the hemorrhoidal cushions to the underlying internal sphincter and thereby it reduces the hemorrhoidal prolapse. It also minimizes the hemorrhoidal blood flow (47).

Nevertheless, the surgical treatment of hemorrhoids is also aimed at removal of the dilated submucus anal venous plexus and fixation of the anal mucosa to the underlying muscle to obliterate submucus space. The procedure of radiofrequency coagulation serves this purpose $(48,49)$.

Unlike staplers and Doppler guided ligator, which are useful only in dealing with hemorrhoids, radiofrequency instrument can be used for performance of other proctological procedures (50). As can be judged from the description of the operative technique, the procedure advocated by us is easy to learn and simple to perform, and obviates the need of a 'learning curve' (51).

The cost of our procedure is limited to acquisition of the radiofrequency generator. The unit does not require any recurring maintenance except the normal care during its handling and use. The running cost of the instrument is negligible. Moreover, with its multidisciplinary usage, the unit could be used by a multi specialty clinic for a variety of applications. Unlike the staplers, no costly disposables are needed.

Comparative findings of SH, DGHAL and our procedure show that a fusion of technique of radiofrequency ablation with fixation of hemorrhoids is not only comparable but also gives better results than the two procedures discussed above (Tables III-V). 
Table III. Comparative evaluation of peri- and postoperative findings in patients with stapled hemorrhoidectomy and radiofrequency ablation and fixation of hemorrhoids

\begin{tabular}{lll}
\hline Observations & $\begin{array}{l}\text { Stapled } \\
\text { hemorrhoidectomy }\end{array}$ & $\begin{array}{l}\text { Radiofrequency } \\
\text { ablation and fixation }\end{array}$ \\
\hline Operative time & $1.5(31)-2.5(52)$ minutes & 7 minutes \\
Hospital stay & $1.7(49)-2.7(31)$ days & $<1$ day \\
Analgesic requirement & $2.6(53)-9.6(54)$ tablets & 20 tablets \\
Pain score & $1.8(26)$ to $3(52)$ & 1 to 5 \\
Incapacity to work & $7-21$ days (55). 1-31 days (49) & $6-14$ days \\
Bleeding control & $78 \%(52)$ to $80 \%(56)$ & $98 \%$ \\
Development of new & $10 \%(29)$ & $4 \%$ \\
$\quad$ symptoms & & $3.5 \%$ \\
Complication rates & $6.4(55)$ to $31 \%(23)$ & \\
\hline
\end{tabular}

Table IV. Comparative evaluation of postoperative complications in patients with stapled hemorrhoidectomy $(\mathrm{SH})$ and radiofrequency ablation and fixation of hemorrhoids (RAF)

\begin{tabular}{lcc}
\hline Complications & SH & RAF \\
\hline Urinary retention & $12 \%(58)$ to $15 \%(25)$ & $4 \%$ \\
Bleeding & $7.6 \%(57)$ & $2 \%$ \\
Anal thrombosis & $3.8 \%(32)$ & $6 \%$ \\
Stricture & $0.8 \%(23)$ to $2 \%(32)$ & $1 \%$ \\
Fissure formation & $0.2 \%(23)$ & None \\
Skin tags & $4 \% 59-8 \%(33)-20 \%(61)$ & $6 \%$ \\
Recurrence & $2.3 \%(23)$ to $7 \%(60)$ & $2 \%$ \\
\hline
\end{tabular}

Table V. Comparative evaluation of postoperative events in patients with Doppler guided hemorrhoidal artery ligation (DGHAL) and radiofrequency ablation and fixation of hemorrhoids (RAF)

\begin{tabular}{lcc}
\hline Observations & DGHAL & RAF \\
\hline Hospital stay & $19.8 \mathrm{~h}(23)$ & $<1$ day \\
Return to activity & 3 days $(23)$ & 8 days \\
Effectiveness of the procedure & $61.2 \%(46)$ to $82.6 \%(49)$ & $98 \%$ \\
Control of pain & $71 \%(48)$ & $98.5 \%$ \\
Control of bleeding & $88 \%(48)$ & $98 \%$ \\
\hline
\end{tabular}

\section{CONCLUSION}

The data presented here provide enough evidence that a combined technique of radiofrequency ablation and fixation of hemorrhoids is quick to perform, easy to learn and bloodless in nature. It is economical for the patient in the sense that no expensive disposables are needed, the hospital stay is short and coupled with an early return to work, and it achieves greater patient satisfaction.

\section{REFERENCES}

1. Milligan ETC, Morgan CN, Jones LE, Officer R. Surgical anatomy of the anal canal and operative treatment of hemorrhoids. Lancet 1937; 2: $1119-24$.

2. Mikuni N, Oya M, Komatsu J, Yamana T. A prospective randomized comparison between an open hemorrhoidectomy and a semi-closed (semi-open) hemorrhoidectomy. Surg Today 2002; 32: 40-7.

3. Farag AE. Pile suture: A new technique for the treatment of hemorrhoids. Br J Surg 1978; 65: 293-5.

4. Awojobi OA. Modified pile suture in the outpatient treatment of hemorrhoids. A preliminary report. Dis Colon Rectum 1983; 26: 95-7.

5. Bhansali A, Kale PC. Plication of hemorrhoids. Indian J Surg 1982; 49: 78-80.

6. Patnaik SP, Mangual R. Plication: A new method of treating piles without knife. Antiseptic 1996; 93: 206-9.

7. Serdev N. The surgical treatment of hemorrhoids. Their suturing ligation without excision. Khirurgiia (Sofiia) 1990; 43 (4): 65-8.

8. Hughes E, Cuthberton A, Killinbach K. In: Colorectal surgery. London: Churchill Livingstone; 1983. p. 178-202.

9. Leicester RJ, Nicholls RJ, Mann CV. Infrared coagulation: A new treatment for hemorrhoids. Dis Colon Rectum 1981; 24: 602-5.

10. Smith LE. Hemorrhoids. A review of current techniques and management. Gastroenterol Clin North Am 1987; 16: 79-91.

11. Leff EL. Hemorrhoidectomy-laser versus non-laser outpatient surgical experience. Dis Colon Rectum 1992; 35: 743-6.

12. Norman DA, Newton R, Nicholas GV. Direct current electrotherapy of internal hemorrhoids: An effective, safe, and painless outpatient approach. Am J Gastroenterol 1989; 84: 482-7.

13. Jensen DM, Jutabha R, Machicado GA, Jensen ME, Cheng S, Gornbein $\mathrm{J}$, et al. Prospective randomized comparative study of bipolar electrocoagulation versus heater probe for treatment of chronically bleeding internal hemorrhoids. Gastrointest Endosc 1997; 46: 435-43.

14. Gupta PJ. Novel technique: Radiofrequency coagulation -a treatment alternative for early-stage hemorrhoids. Gen Med 2002; 4: 1-9.

15. Huang SK. Advances in applications of radiofrequency current to catheter ablation therapy. Pacing Clin Electrophysiol 1991; 14: 28-42.

16. Goldberg SN, Gazelle GS. Radiofrequency tissue ablation: Physical principles and techniques for increasing coagulation necrosis. Hepatogastroenterol 2001; 48: 359-67.

17. Goldberg SN, Gazelle GS, Dawson SL, Rittman WJ, Mueller PR, Rosenthal DI. Tissue ablation with radiofrequency: Effect of probe size, gauge, duration and temperature on lesion volume. Acad Radiol $1995 ; 2: 399-404$

18. Morinaga K, Hasuda K, Ikeda T. A novel therapy for internal hemorrhoids. Ligation of the hemorrhoidal artery with a newly devised instrument (Moricorn) in conjunction with a Doppler flow meter. Am J Gastroenterol 1995; 90: 610-3

19. Milito G, Cortese F, Anselmo A, Casciani U. Treatment of hemorrhoidal peduncles with diathermy probe. Ann Ital Chir 1995; 66: 801-3.

20. Farinetti A, Saviano M, Quaranta N, Monni S. Surgical treatment of hemorrhoidal disease using the circular stapler. Analysis of 60 operated cases. Minerva Chir 2001; 56: 125-31.

21. Thompson WHF. The nature of hemorrhoids. Br J Surg 1975; 624252.

22. Haas PA, Fox TA Jr, Haas GP. The pathogenesis of hemorrhoids. Dis Colon Rectum 1984; 27: 442-50.

23. Ravo B, Amato A, Bianco V, Boccasanta P, Bottini C, Carriero A, et al. Complications after stapled hemorrhoidectomy: Can they be prevented? Tech Coloproctol 2002; 6: 83-8.

24. Kolbert GW, Raulf F. Evaluation of Longo's technique for haemorrhoidectomy by doppler ultrasound measurement of the superior rectal artery. Zentralbl Chir 2002; 127: 19-21.

25. D'Agostino G, Zampogna A, Rognoni M, Ricci A, Garavoglia M. Hemorrhoidectomy in muco-hemorrhoidal prolapse using mechanical stapler. Minerva Chir 2000; 55: 395-9.

26. Kairaluoma M, Nuorva K, Kellokumpu I. Day-case stapled (circular) vs. diathermy hemorrhoidectomy: A randomized, controlled trial evaluating surgical and functional outcome. Dis Colon Rectum 2003; 46: 93-9.

27. Jayne DG, Seow-Choen F. Modified stapled hemorrhoidopexy for the treatment of massive circumferentially prolapsing piles. Tech Coloproctol 2002; 6: 191-3. 
28. Ho YH, Cheong WK, Tsang C, Ho J, Eu KW, Tang CL, et al. Stapled hemorrhoidectomy -cost and effectiveness. Randomized controlled trial including incontinence scoring, anorectal manometry and endoanal ultrasound assessment at up to 3 months. Dis Colon Rectum 2000; 43: 1666-75.

29. Cheetham MJ, Cohen CR, Kamm MA, Phillips RK. A randomized controlled trial of diathermy hemorrhoidectomy vs. stapled hemorrhoidectomy in an intended day-care setting with longer-term followup. Dis Colon Rectum 2003; 46: 491-7.

30. Ganio E, Altomare DF, Gabrielli F, Milito G, Canuti S. Prospective randomized multicentre trial comparing stapled with open haemorrhoidectomy. Br J Surg 2001; 88: 669-74.

31. Pernice LM, Bartalucci B, Bencini L, Borri A, Catarzi S, Kroning K. Early and late (ten years) experience with circular stapler hemorrhoidectomy. Dis Colon Rectum 2001; 44: 836-41.

32. Shalaby R, Desoky A. Randomized clinical trial of stapled versus Milligan-Morgan haemorrhoidectomy. Br J Surg 2001; 88: 104953.

33. Mlakar B, Kosorok P. Complications, and results after stapled haemorrhoidopexy as a day surgical procedure. Tech Coloproctol 2003; 7: 164-7.

34. Wong LY, Jiang JK, Chang SC, Lin JK. Rectal perforation: A lifethreatening complication of stapled hemorrhoidectomy: Report of a case. Dis Colon Rectum 2003; 46: 116-7.

35. Maw A, Eu KW, Seow-Choen F. Retroperitoneal sepsis complicating stapled hemorrhoidectomy: Report of a case and review of the literature. Dis Colon Rectum 2002; 45: 826-8.

36. Bonner C, Prohm P, Storkel S. Fournier gangrene as a rare complication after stapler hemorrhoidectomy. Case report and review of the literature. Chirurg 2001; 72: 1464-6.

37. Hetzer FH, Wildi S, Demartines N. New modalities and concepts in the treatment of hemorrhoids. Schweiz Rundsch Med Prax 2003; 92: 1579-83.

38. Arnold S, Antonietti E, Rollinger G, Scheyer M. Doppler ultrasound assisted hemorrhoid artery ligation. A new therapy in symptomatic hemorrhoids. Chirurg 2002; 73: 269-73.

39. Goligher J, Duthie H, Nixon H. Hemorrhoids, or piles. In: Surgery of the anus rectum and colon. $5^{\text {th }}$ ed. London: Bailliere Tindall; 1992. p. 99.

40. Aigner F, Bodner G, Conrad F, Mbaka G, Kreczy A, Fritsch H. The superior rectal artery and its branching pattern with regard to its clinical influence on ligation techniques for internal hemorrhoids. Am J Surg 2004; 187: 102-8.

41. Lienert M, Ulrich B. Doppler-guided ligation of the hemorrhoidal arteries. Report of experiences with 248 patients. Dtsch Med Wochenschr 2004; 129: 947-50.

42. Bursics A, Morvay K, Kupcsulik P, Flautner L. Comparison of early and 1-year follow-up results of conventional hemorrhoidectomy and hemorrhoid artery ligation: A randomized study. Int J Colorectal Dis 2004; 19: 176-80.

43. Sohn N, Aronoff JS, Cohen FS, Weinstein MA. Transanal hemorrhoidal dearterialization is an alternative to operative hemorrhoidecto- my. Am J Surg 2001; 182: 515-9.

44. Shelygin IUA, Titov AIU, Veselov VV, Kanametov MKH. Results of ligature of distal branches of the upper rectal artery in chronic hemorrhoid with the assistance of Doppler ultrasonography. Khirurgiia (Mosk) 2003; (1): 39-44.

45. Gupta PJ. Use of radiofrequency in the treatment of minor anal pathology. Acta Chir Belg 2004; 104: 313-7.

46. Brown JS. Radiosurgery. In: Minor Surgery a text and atlas. $4^{\text {th }}$ ed. London: Arnold; 1994. p. 324-5.

47. Gupta PJ. Radiofrequency ablation and plication of hemorrhoids. Tech Coloproctol 2003; 7: 45-50.

48. Gupta PJ. Radioablation of advanced grades of hemorrhoids with radiofrequency. Curr Surg 2003; 60: 452-8

49. Gupta PJ. Plication of hemorrhoids after radiofrequency ablation: An alternative to hemorrhoidectomy. Ann Saudi Med 2002; 22: 267-8.

50. Gupta PJ. Radiosurgery: A new tool in the proctology practice. Bratisl Lek Listy 2004; 105: 270-6.

51. Hetzer FH, Schafer M, Demartines N, Clavien PA. Prospective assessment of the learning curve and safety of stapler hemorrhoidectomy. Swiss Surg 2002; 8: 31-6.

52. Palimento D, Picchio M, Attanasio U, Lombardi A, Bambini C, Renda A. Stapled and open hemorrhoidectomy: Randomized controlled trial of early results. World J Surg 2003; 27: 203-7.

53. Racalbuto A, Aliotta I, Corsaro G, Lanteri R, Di Cataldo A, Licata A. Hemorrhoidal stapler prolapsectomy vs. Milligan-Morgan hemorrhoidectomy: A long-term randomized trial. Int J Colorectal Dis 2004; 19: 239-44.

54. Law WL, Tung HM, Chu KW, Lee FC. Ambulatory stapled haemorrhoidectomy: A safe and feasible surgical technique. Hong Kong Med J 2003; 9: 103-7.

55. Arnaud JP, Pessaux P, Huten N, de Manzini N, Tuech JJ, Laurent B, et al. Treatment of hemorrhoids with circular stapler, a new alternative to conventional methods: A prospective study of 140 patients. J Am Coll Surg 2001; 193: 161-5.

56. Correa-Rovelo JM, Téllez O, Obregón L, Miranda-Gómez A, Morán S. Stapled rectal mucosectomy vs. closed hemorrhoidectomy: A randomized, clinical trial. Dis Colon Rectum 2002; 45: 1367-74 (Discussion 1374-5).

57. Hahn M, Simsa J, Horak J. Surgery of hemorrhoids using the Long method and its complications. Rozhl Chir 2003; 82: 307-11.

58. Singer MA, Cintron JR, Fleshman JW, Chaudhry V, Birnbaum EH, Read TE, et al. Early experience with stapled hemorrhoidectomy in the United States. Dis Colon Rectum 2002; 45: 360-7 (Discussion 367-9).

59. Seow-Choen F. Stapled haemorrhoidectomy: Pain or gain. Br J Surg 2001; 88: 1-3

60. Ortiz H, Marzo J, Armendariz P. Randomized clinical trial of stapled haemorrhoidopexy versus conventional diathermy haemorrhoidectomy. Br J Surg 2002; 89: 1376-81.

61. Mehigan BJ, Monson JR, Hartley JE. Stapling procedure for haemorrhoids versus Milligan-Morgan haemorrhoidectomy: Randomised controlled trial. Lancet 2000; 355: 782-5. 